\title{
Prevalence and Determinants of Under-Nutrition Among Under-Five Children in Afar Region, Ethiopia: Evidence From 2016 Ethiopian Demographic and Health Survey
}

Damitie Kebede Mengesha ( $\square$ dakebede10@gmail.com )

Bahir Dar University https://orcid.org/0000-0001-5494-9906

Demewez Moges Haile

Bahir Dar University

\section{Research}

Keywords: Under-five children, stunting, wasting, underweight, Ethiopia

Posted Date: January 10th, 2022

DOl: https://doi.org/10.21203/rs.3.rs-970742/v1

License: (c) (1) This work is licensed under a Creative Commons Attribution 4.0 International License. Read Full License 


\section{Abstract}

Background: Undernutrition is one of the major public health concerns among infants and young children in the country. Childhood under-nutrition is widespread in low and middle-income countries. This study was initiated to assess the prevalence of under-nutrition and its associated factors among under-five children in Afar Region, Ethiopia.

Methods: The data for this study were extracted from the Ethiopian Demographic and Health Survey (EDHS) 2016. The information collected from 937 children born 5 years before the survey was considered in the analysis. A multivariable binary logistic regression analysis was used at a $5 \%$ level of significance to determine the individual- and community-level factors associated with childhood malnutrition.

Results: The prevalence of stunting, underweight and wasting in Afar region were $41.1 \%, 36.2 \%$ and $17.7 \%$, respectively. About $26.7 \%$ of children in Afar region were both stunting and underweight, $12.7 \%$ were both underweight and wasting, $7.6 \%$ were both stunting and wasting and only $7.0 \%$ of children had all the three under-nutrition conditions. Among the factors considered in this study, age of a child in months, anemia level, mothers' BMI, household wealth index, size of child at birth, number of living children and place of residence were significantly associated with stunting, underweight and wasting in Afar Region.

Conclusions: The prevalence of all stunting, underweight and wasting was relatively high. Undernutrition is one of the major public health concerns among children in Afar Region. The effect of these factors should be considered to develop strategies to reduce under-nutrition in the study area. Thus, intervention should be focused on improving the under-nutrition determinants of the children to improve the child's nutritional status and reduce child morbidity and mortality.

\section{Background}

Malnutrition is of public health importance in developing countries and is responsible for over half of child deaths each year from preventable causes [1]. Undernutrition occurs when the diet a person consumes does not meet their body's requirement for growth and development. Good nutrition and feeding practices are critical to a child's growth and development especially during the first two years of life. Undernutrition impairs a child's immunity, which can lead to recurrent infections, and impaired physical and cognitive development [2].

Globally, an estimated 165 million children under five years of age, or $26 \%$, were stunted, 101 million children under five years of age, or $16 \%$, were underweight and 52 million children under five years of age, or $8 \%$, were wasted. High prevalence levels of stunting among children under five years of age in Africa (36\% in 2011) and Asia (27\% in 2011) remain a public health problem, one which often goes unrecognized. More than $90 \%$ of the world's stunted children live in Africa and Asia. Although the prevalence of stunting, underweight and wasting among children under five years of age worldwide has decreased since 1990, overall progress is insufficient and millions of children remain at risk [3]. 
Undernutrition in children occurs due to the interplay of several factors, which include variables related to the maternal age, maternal education, poor feeding practice, maternal nutritional status, parity and multiple births, sex of the child, illness, birth interval and immunization status, poor wealth status, large families, water and sanitation, place of residence, and other factors relating to health services utilization [4-6]. Child under-nutrition and mortality rates are sensible reactions to both wellbeing programs and financial conditions such as pay, unemployment, and lack of education [7]. In Ethiopia, the prevalence of under-nutrition is high which ranges from $14.6 \%$ in Addis Ababa to $46.3 \%$ in Amhara Region for stunting, $3.5 \%$ in Addis Ababa to $22.5 \%$ in Afar region for wasting and $5 \%$ in Addis Ababa to $35.5 \%$ in Afar region for underweight [8-11].

Although a few studies have been carried out on prevalence and identification of factors that are associated with children under five years old of undernutrition in the Afar region, none of them uses the nationally representative data for the Afar region. The exertion made in decreasing under-five children's undernutrition in the region is still high, and more effort is required to move forward the obstructions for advance diminishment. More research studies are, subsequently, required to inform policymakers to execute suitable mediation programs. To address these gaps, an all-inclusive cross-sectional analysis of the recent 2016 Ethiopian Demographic Health Survey (EDHS) was done, to explore the potential risk factors of undernutrition among under-five children in Afar region, Ethiopia.

\section{Methods}

\section{Description of study design and area}

A cross-sectional study design was used for this study. The study was conducted in Afar regional state which is located in the northeastern part of Ethiopia. According to the 2007 Census, the state's population was $1,390,273$ of which 615,156 were females. The urban residents of the region were 185,135 or $13.32 \%$ of the population, a further 409,123 or $29.43 \%$ were pastoralists. The region is well known for its early hominid fossil finds including 'Lucy', an Australopithecus afarensis, discovered in 1974, which lived about 3.2 million years ago and more recently in the summer of 2007 the discovery of hominid remains 3.5 - 3.8 million years old [12].

\section{Data Sources}

The data for this study was extracted from the Ethiopian Demographic and Health Survey (EDHS) 2016. The Central Statistics Agency (CSA), the Ministry of Health ( $\mathrm{MOH})$, and the Ethiopian Public Health Institute together surveyed from January 18, 2016-June 27, 2016, where the United States Agency for International Development (USAID) funded the project. The authors have got permission from the ICFDHS program to use the EDHS data and access it through https://www.dhsprogram.com/data/dataset_admin/login_main.cfm. The 2016 EDHS used a two-stage stratified sampling to select households. In the first stage, there were 645 enumeration areas (202 in urban and 443 in rural areas). 937 (513 males and 424 females) under-five children from Afar region were considered for this study. This study considered live children age 0-59 months with 
anthropometry data in the analysis of determinants of nutritional status among children under age 5 in Afar region. Missing values in the 2016 EDHS dataset were not included in the analyses.

\section{Variables of the study}

The subordinate factors for this consideration were the malnutrition status of under- 5 year children (stunting, underweight and wasting). Children whose height-for-age Z-score is below minus two standard deviations (-2SD) from the median of the reference population is considered as stunted. If the weight-forage Z-score is below minus two standard deviations (-2 SD) from the medium of reference population then the child is underweight. Children whose weight for height Z-score is below minus two standard deviations (-2SD) from the median of the reference population are considered as wasted [10]. Illustrative factors were chosen after conducting a point-by-point writing survey additionally accessible with complete data in the EDHS, 2016 data set was included within the current investigation. Selected illustrative factors were divided into two levels which included socio-demographic-maternal and childlevel variables. Socio demographic-maternal variables chosen were types of residence, household wealth index, mother's educational level, mother's body mass index (BMI), religion, and type of toilet facility, sex of household head and sources of drinking water. Child-level components were the sex of the child, child age, type of birth, number of living children and child size at birth. Malnutrition indicators were defined using the WHO child growth standards [9, 11, 13-15].

\section{Statistical data analysis}

The data was extracted, edited, and analyzed by using SPSS version 23 for Windows. Descriptive statistics such as frequencies and proportions were used to summarize the distribution of selected background characteristics of the sample. Bivariate logistic regression was performed to analyze the crude odds ratio and a variable with a P-value of less than 0.25 was transported into multivariable binary logistic regression analyses to analyze adjusted odds ratio and to identify the determinants of undernutrition of children under five years old. The dependent variables for bivariate and multivariable logistic regression analyses were stunting, wasting and underweight. Finally, variables with P-values < 0.05 in the multivariable logistic regression model were taken as statistically significant.

\section{Results}

A total of 937 under-five children were included in this study. The prevalence of stunting, underweight and wasted in Afar region were $41.1 \%, 36.2 \%$ and $17.7 \%$, respectively. About $26.7 \%$ of children in Afar region were both stunted and underweight, $12.7 \%$ were both underweight and wasted, $7.6 \%$ were both stunted and wasted and only $7.0 \%$ of children had all three under-nutrition conditions. Of the participating children, 383 (40.9\%) were 0-24 months old, 362 (38.6\%) were 25-47 months old and 190 (20.3\%) were 48-59 months old. Of the total participants, 513 (54.7\%) were male, and nearly 855 (91.2\%) of the children were taken from rural areas. Most of (98\%) the children were born in single birth type. Under mothers' BMI categories, overweight, normal weight and underweight were $4.6 \%, 53.7 \%$ and $41.7 \%$, respectively. More than half $(55.3 \%)$ of children were small size at birth, $29.6 \%$ and $15.2 \%$ of the children were medium 
and large size at birth, respectively. About $81.8 \%$ of the children's families did not have toilet facilities, and the majorities $(64.2 \%)$ of household heads were males. Most $(88.3 \%)$ of children whose parents were poor wealth indexed, $1.5 \%$ and $10.2 \%$ were medium and reach, respectively. The number of children who lived in household members of $1-2,3-4$ and $>4$ was $33.3 \%, 32.0 \%$ and $34.7 \%$, respectively. Most of (91.2\%) the children's households accessed unimproved water. Of the total participants, $72.8 \%$ of the children were anemic.

\section{Factors associated with stunting}

Results of the multivariable binary logistic regression model revealed that age of the child, household wealth index, number of living children and anemia level were significantly associated with being stunted. The risk of being stunted was 2.32 and 2.10 times more likely among children that were aged 25-47 and 48-59 as compared to those aged 0-24 months, respectively. Children from the household who had rich and medium wealth index were 0.66 and 0.63 times less likely to be stunted as compared to the children household who had poor wealth index. The number of children who lived in household members $>4$ was 1.68 times more likely to be stunted compared to the number of children who lived in household members 1-2. Being stunted of anemic children was 1.91 times more likely to develop stunting as compared to non-anemic children.

Table 1. Bivariate and multivariable logistic regression of determinants associated with stunting on childhood under 5 years old in Afar Region, Ethiopia, EDHS 2016 
Variables

Stunting $\quad$ COR $(95 \%$

$\mathrm{Cl})$

AOR (95\% Cl) P-value

Yes No

\section{Age of child in months}

\begin{tabular}{|c|c|c|c|c|c|}
\hline $0-24$ & $\begin{array}{l}118 \\
(30.8 \%)\end{array}$ & $\begin{array}{l}265 \\
(69.2 \%)\end{array}$ & 1 & 1 & \\
\hline $25-47$ & $\begin{array}{l}172 \\
(49.2 \%)\end{array}$ & $\begin{array}{l}184 \\
(50.8 \%)\end{array}$ & $\begin{array}{l}2.32(1.72 \\
3.13)\end{array}$ & $\begin{array}{l}2.32(1.63 \\
3.30) \star \star \star\end{array}$ & $<0.0001$ \\
\hline $48-59$ & $\begin{array}{l}83 \\
(43.7 \%)\end{array}$ & $\begin{array}{l}107 \\
(56.3 \%)\end{array}$ & $\begin{array}{l}1.74(1.22, \\
2.50)\end{array}$ & $\begin{array}{l}2.10(1.36 \\
3.22)^{\star \star}\end{array}$ & 0.001 \\
\hline
\end{tabular}

Sex of child

Male

221

$(43.1 \%)$

Female

\section{4}

$(38.7 \%)$

\section{2}

$(56.9 \%)$

\section{0}

(61.3\%)

1

1

$0.83(0.64, \quad 0.86(0.64$

1.08)

\section{Place of residence}

\begin{tabular}{lllll} 
Urban & 27 & 55 & 1 & 1 \\
& $(32.9 \%)$ & $(67.1 \%)$ & & \\
\hline Rural & 358 & 497 & $1.47(0.91$, & $0.47(0.14$, \\
& $(41.9 \%)$ & $(58.1 \%)$ & $2.37)$ & $1.53)$
\end{tabular}

\section{Type of birth}

Single birth

Multiple birth

\section{Mothers` BMI}

Overweight

Normal weight

Under weight

\section{Size of child at birth}

$$
\text { Large }
$$

Medium
375

$(40.8 \%)$

$9(47.4 \%)$

\section{3}

$(59.2 \%)$

\section{0}

(52.6\%)
$1.61(0.65$, 3.40)
1

1.41 (0.53, 3.71) 
Small

$\begin{array}{llll}219 & 299 & 1.27(0.86, & 1.52 \\ (43.2 \%) & (57.7 \%) & 1.86) & 2.35)\end{array}$

\section{Present of toilet facility}

\begin{tabular}{lllll}
\hline Yes & $\begin{array}{l}69 \\
(40.4 \%)\end{array}$ & $\begin{array}{l}102 \\
(59.6 \%)\end{array}$ & 1 & 1 \\
\hline No & 316 & 450 & $1.04(0.74$, & $1.19(0.77$, \\
& $(41.3 \%)$ & $(58.7 \%)$ & $1.46)$ & $1.83)$
\end{tabular}

Sex of household head

\begin{tabular}{lllll} 
& 245 & 357 & 1 & 1 \\
\hline Male & $(40.7 \%)$ & $\begin{array}{l}(59.3 \%) \\
\text { Female }\end{array}$ & & \\
\hline & 140 & 195 & $1.05(0.80$, & $1.01(0.73$, \\
& $(41.8 \%)$ & $(58.2 \%)$ & $1.37)$ & $1.38)$
\end{tabular}

Household wealth index combined

\begin{tabular}{|c|c|c|c|c|c|}
\hline Poor & $\begin{array}{l}352 \\
(42.6 \%)\end{array}$ & $\begin{array}{l}475 \\
(57.4 \%)\end{array}$ & 1 & 1 & \\
\hline Medium & $2(14.3 \%)$ & $\begin{array}{l}12 \\
(85.7 \%)\end{array}$ & $\begin{array}{l}0.23(0.05 \\
1.01)\end{array}$ & $\begin{array}{l}0.37(0.04 \\
3.85)\end{array}$ & \\
\hline Rich & $\begin{array}{l}31 \\
(32.3 \%)\end{array}$ & $\begin{array}{l}65 \\
(67.7 \%)\end{array}$ & $\begin{array}{l}0.64(0.41 \\
1.01)\end{array}$ & $\begin{array}{l}0.34(0.11 \\
0.98)^{\star}\end{array}$ & 0.047 \\
\hline \multicolumn{6}{|c|}{ Number of living children } \\
\hline $1-2$ & $\begin{array}{l}134 \\
(42.9 \%)\end{array}$ & $\begin{array}{l}178 \\
(57.1 \%)\end{array}$ & 1 & 1 & \\
\hline $3-4$ & $\begin{array}{l}130 \\
(43.3 \%)\end{array}$ & $\begin{array}{l}170 \\
(56.7 \%)\end{array}$ & $\begin{array}{l}1.02(0.74, \\
1.40)\end{array}$ & $\begin{array}{l}0.86(0.59 \\
1.26)\end{array}$ & \\
\hline$>4$ & $\begin{array}{l}121 \\
(37.2 \%)\end{array}$ & $\begin{array}{l}204 \\
(62.8 \%)\end{array}$ & $\begin{array}{l}1.79(1.57, \\
3.08)\end{array}$ & $\begin{array}{l}1.68(1.46 \\
2.99)^{*}\end{array}$ & 0.044 \\
\hline
\end{tabular}

\section{Sources of drinking water}

\begin{tabular}{|c|c|c|c|c|}
\hline Improved & $\begin{array}{l}110 \\
(44.4 \%)\end{array}$ & $\begin{array}{l}138 \\
(55.6 \%)\end{array}$ & 1 & 1 \\
\hline Unimproved & $\begin{array}{l}275 \\
(39.9 \%)\end{array}$ & $\begin{array}{l}414 \\
(60.1 \%)\end{array}$ & $\begin{array}{l}0.83(0.62, \\
1.12)\end{array}$ & $\begin{array}{l}0.83(0.57, \\
1.22)\end{array}$ \\
\hline
\end{tabular}

\section{Anemia level}

Non-anemic

$\begin{array}{ll}73 & 110 \\ (39.9 \%) & (60.1 \%)\end{array}$

Anemic

$\begin{array}{ll}273 & 288 \\ (48.7 \%) & (51.3 \%)\end{array}$

$1.59(1.13$ 2.23)

$1.91(1.33$, $2.75)^{\star \star \star}$ 
AOR: adjusted odds ratio; COR: crude odds ratio; Cl: confidence interval; * significant $p$ value $<0.05$; ** significant $p$ value $<0.01 ; * * *$ significant $p$ value $<0.001,1=$ reference

\section{Factors associated with underweight}

According to the multivariable logistic regression analysis, age of child, place of residence, mothers' BMI, household wealth index and anemia level were significantly associated with underweight. The children who were 25-47 and 48-59 aged groups were 2.29 and 2.00 times more likely to develop underweight as compared to those who were 0-24 aged groups. The children living in rural areas were 1.98 times more likely to develop underweight as compared to the children living in urban areas. Children who were born underweight and normal-weight mothers were 3.20 and 4.64 times more likely to be underweight compared to children born from overweight mothers. Compared to children from the poor household wealth index, the odds of medium and rich household wealth index were 0.87 and 0.49 times lower. The anemic children were 1.96 times more likely to be underweight as compared to non-anemic children.

Table 2. Bivariate and multivariable logistic regression of risk factors associated with under-weight on childhood less than 5 years in Afar Region, Ethiopia, EDHS 2016 
Variables

Underweight $\quad$ COR $(95 \% \quad$ AOR $(95 \% \mathrm{Cl}) \quad$ P-value

Cl)

Yes No

Age of child in months

\begin{tabular}{llllll}
$0-24$ & 116 & $267(69.7 \%)$ & 1 & 1 & \\
& $(30.3 \%)$ & & & & \\
$25-47$ & 148 & $214(59.1 \%)$ & $\begin{array}{l}1.59(1.18, \\
2.15)\end{array}$ & $\begin{array}{l}2.29(1.61, \\
3.24)^{\star \star \star}\end{array}$ & $<0.0001$ \\
& $(40.9 \%)$ & & & \\
$48-59$ & 75 & $115(60.5 \%)$ & $1.50(1.04$, & $2.00(1.31$, & 0.001 \\
& $(39.5 \%)$ & & $2.16)$ & $3.05)^{\star \star \star}$ & \\
\hline
\end{tabular}

Sex of child

\begin{tabular}{lllll} 
Male & $\begin{array}{l}190 \\
(37.0 \%)\end{array}$ & $323(63.0 \%)$ & 1 & 1 \\
\hline Female & & & \\
& $\begin{array}{llll}149 \\
(35.1 \%)\end{array}$ & $275(64.9 \%)$ & $0.92(0.70$, & $0.98(0.72$, \\
& & & $1.20)$ & $1.33)$
\end{tabular}

Place of residence

\begin{tabular}{llllll} 
Urban & 19 & $63(76.8 \%)$ & 1 & 1 & \\
& $(23.2 \%)$ & & & & \\
Rural & 320 & $535(62.6 \%)$ & $0.46(0.14$, & $1.98(1.17$, & 0.012 \\
& $(37.4 \%)$ & & $1.47)$ & $3.37)^{\star}$ & \\
\hline
\end{tabular}

\section{Type of birth}

Single birth

332

$(36.2 \%)$

Multiple birth

7

\section{Mothers` BMI}

Over weight

Normal weight

Under weight

\section{Size of child at birth}

$$
\text { Large }
$$

Medium
6

$(14.0 \%)$

172

(34.2\%)

152

$(42.9 \%)$
$586(63.8 \%) \quad 1$

$12(63.2 \%)$

$1.03(0.40$

2.64)
$0.92(0.34$, 2.47)
1

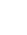


Small

198

$(38.2 \%)$
$320(61.8 \%)$

$1.33(0.90$, 1.98)

$1.52(0.98$,
$2.34)$

\section{Present of toilet facility}

\begin{tabular}{lllll}
\hline Yes & 65 & $106(62.0 \%)$ & 1 & 1 \\
& $(38.0 \%)$ & & & \\
\hline No & 274 & $492(64.2 \%)$ & $\begin{array}{l}0.91(0.65, \\
1.28)\end{array}$ & $0.87(0.56,1.35)$ \\
\hline
\end{tabular}

Sex of household head

\begin{tabular}{lllll} 
Male & 210 & $392(65.1 \%)$ & 1 & 1 \\
\hline Female & $(34.9 \%)$ & & & \\
\hline & 129 & $206(61.5 \%)$ & $1.17(0.89$, & $1.20(0.87$, \\
& $(38.5 \%)$ & & $1.54)$ & $1.64)$
\end{tabular}

Household wealth index combined

\begin{tabular}{|c|c|c|c|c|c|}
\hline Poor & $\begin{array}{l}315 \\
(38.1 \%)\end{array}$ & $512(61.9 \%)$ & 1 & 1 & \\
\hline Medium & $1(7.1 \%)$ & $13(92.9 \%)$ & $\begin{array}{l}0.32(0.03, \\
3.37)\end{array}$ & $\begin{array}{l}0.13(0.02 \\
0.96)^{\star}\end{array}$ & 0.046 \\
\hline Rich & $\begin{array}{l}23 \\
(24.0 \%)\end{array}$ & $73(76.0 \%)$ & $\begin{array}{l}0.35(0.12 \\
1.02)\end{array}$ & $\begin{array}{l}0.51(0.31 \\
0.84)^{\star \star}\end{array}$ & 0.007 \\
\hline \multicolumn{6}{|c|}{ Number of living children } \\
\hline $1-2$ & $\begin{array}{l}111 \\
(35.6 \%)\end{array}$ & 201 (64.4\%) & 1 & 1 & \\
\hline $3-4$ & $\begin{array}{l}115 \\
(38.3 \%)\end{array}$ & $185(61.7 \%)$ & $\begin{array}{l}1.09(0.74 \\
1.61)\end{array}$ & $\begin{array}{l}1.13(0.81, \\
1.56)\end{array}$ & \\
\hline$>4$ & $\begin{array}{l}113 \\
(34.8 \%)\end{array}$ & $212(65.2 \%)$ & $\begin{array}{l}0.99(0.97 \\
1.47)\end{array}$ & $\begin{array}{l}0.96(0.70 \\
1.34)\end{array}$ & \\
\hline
\end{tabular}

\section{Sources of drinking water}

\begin{tabular}{lllll} 
Improved & $\begin{array}{l}84 \\
(33.9 \%)\end{array}$ & $164(66.1 \%)$ & 1 & 1 \\
\hline Unimproved & & & \\
& 255 & $434(63.0 \%)$ & $1.15(0.85$, & $1.37(0.93$, \\
& $(37.0 \%)$ & & $1.56)$ & $2.03)$
\end{tabular}

\section{Anemia level}

Non-anemic

57

(31.1\%)

Anemic

248

(44.2\%)
$126(68.9 \%) \quad 1$

$313(55.8 \%)$
$1.75(1.23$

2.50)
1

$1.96(1.35, \quad<0.0001$
$2.85)^{\star \star *}$ 
AOR: adjusted odds ratio; COR: crude odds ratio; Cl: confidence interval; * significant $p$ value $<0.05$; ** significant $p$ value $<0.01 ; * * *$ significant $p$ value $<0.001,1=$ reference

\section{Factors associated with wasting}

Based on multivariable logistic regression analysis, age of the child, size of child at birth, number of living children and anemia level were significantly associated with wasting. The results of adjusted showed that the children who were 25-47 and 48-59 aged groups were 2.34 and 2.13 times more likely to develop underweight as compared to those who were 0-24 aged groups. Children who were born with small size were 2.07 times more likely to be underweight than children who were born larger. The number of children who lived in household members $>4$ was 1.81 times more likely to be wasting compared to the number of children who lived in household members 1-2. The odds of being underweight were 1.94 times higher among anemic children compared to non-anemic children.

Table 3 Bivariate and multivariate logistic regression of risk factors associated with wasting on childhood less than 5 years old in Afar Region, Ethiopia. 
Variables

wasting $\quad \operatorname{COR}(95 \% \mathrm{Cl}) \quad$ AOR $(95 \% \mathrm{Cl}) \quad$ P-value

Yes No

Age of child in months

$\begin{array}{llllll}0-24 & 99 & 284 & 1 & & \\ & (25.8 \%) & (74.2 \%) & & & \\ 25-47 & 42 & 320 & 0.38(0.25, & 2.34(1.65, & <0.0001 \\ & (11.6 \%) & (88.4 \%) & 0.56) & 3.33)^{\star \star \star} & \\ 48-59 & 25 & 165 & 0.44(0.27, & 2.13(1.38, & 0.001 \\ & (13.2 \%) & (86.8 \%) & 0.70) & 3.28)^{\star \star \star} & \end{array}$

Sex of child

Male

426

1

1

$(17.0 \%) \quad(83.0 \%)$

Female

$\begin{array}{llll}79 & 345 & 1.12(0.80, & 1.28(0.87, \\ (17.0 \%) & (81.4 \%) & 1.57) & 1.89)\end{array}$

Place of residence

Urban

11

$(13.4 \%)$

(86.6\%)

Rural

$\begin{array}{llll}155 & 700 & 0.99(0.19, & 1.43(0.74, \\ (18.1 \%) & (81.9 \%) & 5.00) & 2.76)\end{array}$

\section{Type of birth}

Single birth

Multiple birth

\section{Mothers` BMI}

Over weight

Normal weight

Under weight
164

(17.9\%)

754

(82.1\%)

2 (10.5\%)
17

(89.5\%)

\section{1}

1

$1.43(0.74$ 
Small

$108 \quad 410$

$(20.8 \%)$

1.91 (1.00,

3.64)

2.07 (1.18,

$3.64)^{\star}$

0.011

\section{Present of toilet facility}

\begin{tabular}{lllll} 
Yes & 37 & 134 & 1 & 1 \\
& $(21.6 \%)$ & $(78.4 \%)$ & & \\
\hline No & 129 & 637 & $0.73(0.49$, & $0.63(0.36$, \\
& $(16.8 \%)$ & $(83.2 \%)$ & $1.11)$ & $1.10)$ \\
\hline
\end{tabular}

Sex of household head

\begin{tabular}{lllll} 
Male & 98 & 504 & 1 & 1 \\
& $(16.3 \%)$ & $(83.7 \%)$ & & \\
\hline Female & 68 & 267 & $1.31(0.93$, & $1.37(0.92$, \\
& $(20.3 \%)$ & $(79.7 \%)$ & $1.85)$ & $2.03)$ \\
\hline
\end{tabular}

\section{Household wealth index} combined

\begin{tabular}{|c|c|c|c|c|}
\hline Poor & $\begin{array}{l}152 \\
(18.4 \%)\end{array}$ & $\begin{array}{l}675 \\
(81.6 \%)\end{array}$ & 1 & 1 \\
\hline Medium & $1(7.1 \%)$ & $\begin{array}{l}13 \\
(92.9 \%)\end{array}$ & $\begin{array}{l}0.34(0.04 \\
2.63)\end{array}$ & $\begin{array}{l}0.36(0.04 \\
3.74)\end{array}$ \\
\hline Rich & $\begin{array}{l}13 \\
(13.5 \%)\end{array}$ & $\begin{array}{l}83 \\
(86.5 \%)\end{array}$ & $\begin{array}{l}0.70(0.38 \\
1.28)\end{array}$ & $\begin{array}{l}0.67(0.40 \\
1.13)\end{array}$ \\
\hline
\end{tabular}

\section{Number of living children}

\begin{tabular}{|c|c|c|c|c|c|}
\hline $1-2$ & $\begin{array}{l}61 \\
(19.6 \%)\end{array}$ & $\begin{array}{l}251 \\
(80.4 \%)\end{array}$ & 1 & 1 & \\
\hline $3-4$ & $\begin{array}{l}55 \\
(18.3 \%)\end{array}$ & $\begin{array}{l}245 \\
(81.7 \%)\end{array}$ & $\begin{array}{l}0.92(0.62, \\
1.39)\end{array}$ & $\begin{array}{l}093(0.57 \\
1.51)\end{array}$ & \\
\hline$>4$ & $\begin{array}{l}50 \\
(15.4 \%)\end{array}$ & $\begin{array}{l}275 \\
(84.6 \%)\end{array}$ & $\begin{array}{l}1.75(1.50, \\
3.13)\end{array}$ & $\begin{array}{l}1.81(1.67 \\
2.98)^{\star}\end{array}$ & 0.031 \\
\hline \multicolumn{6}{|c|}{ Sources of drinking water } \\
\hline Improved & $\begin{array}{l}37 \\
(14.9 \%)\end{array}$ & $\begin{array}{l}211 \\
(85.1 \%)\end{array}$ & 1 & 1 & \\
\hline Unimproved & $\begin{array}{l}129 \\
(18.7 \%)\end{array}$ & $\begin{array}{l}560 \\
(81.3 \%)\end{array}$ & $\begin{array}{l}1.31(0.88, \\
1.96)\end{array}$ & $\begin{array}{l}1.45(0.86 \\
2.43)\end{array}$ & \\
\hline \multicolumn{6}{|l|}{ Anemia level } \\
\hline Non-anemic & $\begin{array}{l}22 \\
(12.0 \%)\end{array}$ & $\begin{array}{l}161 \\
(88.0 \%)\end{array}$ & 1 & 1 & \\
\hline Anemic & $\begin{array}{l}116 \\
(20.7 \%)\end{array}$ & $\begin{array}{l}445 \\
(79.3 \%)\end{array}$ & $\begin{array}{l}1.91(1.17, \\
3.11)\end{array}$ & $\begin{array}{l}1.94(1.35 \\
2.80)^{\star \star \star}\end{array}$ & $<0.0001$ \\
\hline
\end{tabular}


AOR: adjusted odds ratio; COR: crude odds ratio; Cl: confidence interval; * significant $\mathrm{p}$ value $<0.05$; ** significant $p$ value $<0.01 ; * * *$ significant $p$ value $<0.001,1=$ reference

\section{Discussion}

This result indicated that the prevalence of stunting in Afar region was $41.1 \%$. In this study, stunting is higher than that of the studies conducted in Ethiopia which were 38.3\% [13], Tigray region $39.1 \%$ [16], Dale district 25.6\% [17], Takusa district 36.5\% [18]; but lower than previously reported stunting (46.9\%) in Tigray region [19], (46.3\%) Amhara region [20], (47.6\%) Oromia region [21], and (44.7\%) east Gojjam Zone [22]. The prevalence of stunting in this study is also higher than the finding reported in Nairobi Peri-Urban Slum 30.2\% [23], but lower than in Nigeria (47.6\%) [24]. This could be because the households lack knowledge, attitude and practices (KAP) on how to feed their children and themselves [25].

This result showed that the prevalence of underweight in Afar region was $36.2 \%$. In this study, underweight is higher than that of the studies conducted in Ethiopia which was 23.3\% [13], Tigray region 23.9\% [16], Dale district 19\% [17], Takusa district 19.5\% [18], Nairobi Peri-Urban Slum 14.9\% [23], Tigray region (33\%) [19], Hidabu Abote District 30.9\% [21], Nigeria 25.6\% [24]. While studies in the Bure Town of West Gojjam Zone [26] and east Gojjam Zone [22] reported a lower prevalence of underweight (14.30\%) and $15.3 \%$. This might be because there is a difference in barriers to under-nutrition such as cultural differences and other socio-demographic characteristics. This might be due to there is a difference in barriers to under-nutrition such as cultural differences and other socio-demographic characteristics.

This result revealed that the prevalence of wasting in Afar region was $17.7 \%$. The prevalence of wasting in this study is higher compared to the study conducted in Ethiopia 10.1\% [13], in Haramaya district 10.7\% [27], in Dale Woreda 14\% [17], in Pakistan 10.7\% [25] and Nairobi Peri-Urban slum 4.5\% [23]. This divergence might be due to the difference in socioeconomic background, variation in sample size, dietary habits and type of meals among the study population. Similar studies conducted in Hidabu Abote District in the Oromia region reported an equivalent finding (16.7\%) [21]. While studies in the Bure Town of West Gojjam Zone, Amhara region [26] and east Gojjam Zone [22] reported lower prevalence of wasting $(11.1 \%)$ and $(10 \%)$. This could be due to there is a difference in obstacles to under-nutrition such as cultural differences and other socio-demographic characteristics.

About $26.7 \%$ of children in Afar region were both stunted and underweight, $12.7 \%$ were both underweight and wasted, $7.6 \%$ were both stunted and wasted and only $7.0 \%$ of children had all three under-nutrition conditions. The prevalence of both stunted and underweight in this study is higher than compared to the study conducted in Ethiopia 19.47\% [13] and Amhara region (23.1\%) [20], but much higher than the study conducted in Kilimanjaro Region, Tanzania 33\% [28]. The prevalence of both underweight and wasting at this finding is higher than the study finding in Amhara region (7.3\%) [20]. The variation might be due to socioeconomic background, geographical characteristics of the study area, access to health care, cultural difference in dietary habits and care practices. 
Results of the multivariable binary logistic regression model revealed that age of the child, household wealth index, number of living children and anemia level were significantly associated with being stunted. The risk of being stunted was 2.32 and 2.10 times more likely among children that were aged 25-47 and 48-59 as compared to those aged 0-24 months, respectively. This finding is in agreement with the studies conducted in Ethiopia [13], in Amhara region (36) in Haramaya district [27], in Pakistan [25] and in Kilimanjaro Region, Tanzania [28], but disagreed with the study conducted in Tigray region [16]. This could be because younger children are more likely to receive more attention and feeding effort from their parents as compared to older children [2]. It could also be due to the inappropriate and late introduction of low nutritional quality supplementary food [29]. Children from the household who had rich and medium wealth index were 0.66 and 0.63 times less likely to be stunted as compared to the children household who had poor wealth index. This finding is in agreement with the studies conducted in Ethiopia [13], Tigray region [16] and Pakistan [25]. This fining is also supported by the literature that reported that the poor wealth index is strongly correlated with under-five stunting [15, 26, 30-32]. The possible explanation for this might be mothers from households having a rich or middle wealth status were more likely to provide micronutrients in reached foods and seek medical treatment for their children. Furthermore, better households have better access to food and higher cash incomes than poor households, allowing them a quality diet, better access to medical care, and more money to spend on essential non-food items such as hygiene products [33]. The number of children who lived in household members $>4$ was 1.68 times more likely to be stunted compared to the number of children who lived in household members 1-2. This finding is in agreement with the study conducted in Amhara region [20] and in Haramaya district [27]. This may be because a large number of children are widely regarded as a risk factor for stunting particularly for infants and young children due to food insecurity. Households with fewer children could be expected to be more capable than households with higher real income to provide their members with an adequate dietary intake [34]. Being stunted of anemic children was 1.91 times more likely to develop stunting as compared to non-anemic children. This finding is supported by the study conducted in Ethiopia [13]. This is because the anemia causes the children to reduce feed intake and leads to malnutrition. Undernourished children are more suffered from inadequate bioavailability of micronutrients such as iron, B12 and folate in their body which are important for the formation of blood cells. Therefore, those children who are undernourished cannot form adequate blood cells as much as required; consequently the this leads to the development of nutritional deficiency anemia which is common especially in developing countries [35].

According to the multivariable logistic regression analysis, age of child, place of residence, mothers' BMI, household wealth index and anemia level were significantly associated with underweight. The children who were 25-47 and 48-59 aged groups were 2.29 and 2.00 times more likely to develop underweight as compared to those who were 0-24 aged groups. This finding is in line with the study conducted in Ethiopia [13] but in contradiction to the study conducted in Tigray region [16] and in Pakistan [25]. It might be due to a large portion of guardians in rural areas are ignoring to meet their children's optimal food requirements like the age of the child increases [36]. The children living in rural areas were 1.98 times more likely to develop underweight as compared to the children living in urban areas. This report is 
supported with the studies conducted in Takusa district, Northwest Ethiopia [18], in Haramaya District, Eastern Ethiopia [27], but against in Pakistan [25] and Tigray region [16]. While ample evidence documents that urban children generally have better nutritional status than their rural children. The environment, choices, and opportunities of urbanites differ greatly from those of rural dwellers' from employment conditions to social and family networks to access to health care and other services [13]. Children who were born underweight and normal-weight mothers were 3.20 and 4.64 times more likely to be underweight compared to children born from overweight mothers. This finding is supported by the studies conducted in Ethiopia [13], in Haramaya District, Eastern Ethiopia [27], in Pakistan [25]. Compared to children from the poor household wealth index, the odds of medium and rich household wealth index were 0.87 and 0.49 times lower. This finding is supported by the studies conducted in Ethiopia [13], in Tigray region [16] and Pakistan [25]. This could be explained by the presence of an intergenerational link between maternal and child nutrition means a small mother will have small babies who in turn grow to become small mothers [37]. Maternal BMI is also an important determinant of child under-nutrition and is influenced by maternal nutrition, to improve child growth, proper nutrition is essential for the mothers during the prenatal and postnatal period. Healthier mothers have less risk of having undernourished children [15]. The anemic children were 1.96 times more likely to be underweight as compared to nonanemic children. This finding is in line with the study conducted in Ethiopia [13]. Those children who are undernourished cannot form adequate blood cells as much as required; consequently, this leads to the development of nutritional deficiency anemia which is common especially in developing countries [35].

Based on multivariable logistic regression analysis, age of the child, size of child at birth, number of living children and anemia level were significantly associated with wasting. The results of adjusted showed that the children who were 25-47 and 48-59 aged groups were 2.34 and 2.13 times more likely to develop underweight as compared to those who were 0-24 aged groups. This report is in line with the study conducted in Tigray region [16], in Haramaya District, Eastern Ethiopia [27], in Dale Woreda, southern Ethiopia [17] and Kilimanjaro Region, Tanzania [28]. The reason might be when the children get grown-up the parent care may be reduced and the children may not get sufficient and balanced meals timely. This could be because younger children are more likely to receive more attention and feeding effort from their parents as compared to older children [2]. Children who were born with small size were 2.07 times more likely to be underweight than children who were born larger. This finding is supported by the studies conducted in Amhara region [20] and in Pakistan [25]. This is might be for the reason that low birth weight is in turn associated with a range of adverse outcomes of first childhood life. The number of children who lived in household members $>4$ was 1.81 times more likely to be wasting compared to the number of children who lived in household members 1-2. This finding is in line with the study conducted in Dale Woreda, southern Ethiopia [17]. Households with fewer children could be expected to be more capable than households with higher real income to provide their members with an adequate dietary intake [34]. The odds of being underweight were 1.94 times higher among anemic children compared to non-anemic children. This finding is consistent with the study conducted in Ethiopia [13].

\section{Conclusions}


This study explored individual- and community-level factors that determined childhood malnutrition in Afar region children. Among the factors considered in this study, age of the child in months, anemia level, size of child at birth, mothers' BMI, household wealth index, number of living children and place of residence were significantly associated with stunting, underweight and wasting. The authors concluded that under-nutrition among under-five children was one of the public health problems in the study area. Thus, interventions should be focused on 25-59 months age of children, poor household wealth index, $>4$ children per household, rural children, children born from underweight mothers, small size child at birth and anemic children to improve the child's nutritional status, and reduce child morbidity and mortality.

\section{Abbreviations}

AOR: adjusted odds ratio; BMI: body mass index; COR: crude odds ratio; CSA: Central Statistical Agency; SPSS: Statistical Package for Social Science; DHS: Demographic and Health Surveys; EDHS: Ethiopian Demographic and Health Survey.

\section{Declarations}

\section{Ethics approval and consent to participate}

Ethics approval and consent to participate The EDHS 2016 has taken into account the standard ethical guidelines of the measure DHS program. The authors have obtained the data from the measure DHS website (https://www.dhsprogram.com/data/dataset_admin/index.cfm) following their data obtaining procedure. The formal ethical clearance was obtained from the Demographic and Health Surveys (DHS) program.

\section{Consent for publication}

Not applicable.

\section{Availability of data and materials}

The data set used and analyzed during the current study is available from the corresponding author on reasonable request (in SPSS code).

\section{Competing interests}

The authors declare that they have no competing interests.

\section{Funding}

No funding was obtained for this study.

\section{Authors' contributions}


DK conceived the idea, drafts the manuscript and interpreted the results. DK performed the statistical analysis and help in results interpretation and writing. DK critically reviewed the manuscript.

\section{Acknowledgments}

The authors would like to thank Ethiopia Central Statistical Agency for permitting us to use the data for our study.

\section{References}

1. Collins $S$, et al. Management of severe acute malnutrition in children. The lancet. 2006;368(9551):1992-2000.

2. Gudu E, et al. Factors associated with malnutrition in children $<5$ years in western Kenya: a hospitalbased unmatched case control study. BMC nutrition. 2020;6(1):1-7.

3. United Nations Children's. Fund WHO, The World Bank, UNICEF-WHO-World Bank joint child malnutrition estimates. 2012; UNICEF New York, NY, USA.

4. Obstetric EE, Care N, Assessment 2016: Final Report. Ethiopian Public Health Institute, Addis Ababa, Ethiopia. 2016.

5. Younis K, Ahmad S, Badpa A. Malnutrition: causes and strategies. J Food Process Technol. 2015;6(434):2.

6. Blossner M, De Onis M, Prüss-Üstün A. Malnutrition: quantifying the health impact at national and local levels. World Health Organization; 2005.

7. El-Ghannam AR. The global problems of child malnutrition and mortality in different world regions. Journal of health social policy. 2003;16(4):1-26.

8. Edris M. Assessment of nutritional status of preschool children of Gumbrit, North West Ethiopia. Ethiopian Journal of Health Development. 2007;21(2):125-9.

9. Muchie KF. Quality of antenatal care services and completion of four or more antenatal care visits in Ethiopia: a finding based on a demographic and health survey. BMC Pregnancy Childbirth. 2017;17(1):1-7.

10. Tarekegn SM, Lieberman LS, Giedraitis V. Determinants of maternal health service utilization in Ethiopia: analysis of the 2011 Ethiopian Demographic and Health Survey. BMC Pregnancy Childbirth. 2014;14(1):1-13.

11. Wolde HF, et al. Factors affecting neonatal mortality in the general population: evidence from the 2016 Ethiopian Demographic and Health Survey (EDHS) - multilevel analysis. BMC Res Notes. 2019;12(1):1-6.

12. Commission, FDR.o.EPC, Summary and Statistical report of the 2007 population and housing census. Addis Ababa, Ethiopia. 2008.

13. Tekile AK, Woya AA, Basha GW. Prevalence of malnutrition and associated factors among under-five children in Ethiopia: evidence from the 2016 Ethiopia Demographic and Health Survey. BMC Res 
Notes. 2019;12(1):1-6.

14. Tariq J, et al. Factors associated with undernutrition in children under the age of two years: secondary data analysis based on the Pakistan demographic and health survey 2012-2013. Nutrients. 2018;10(6):676.

15. Talukder A. Factors associated with malnutrition among under-five children: illustration using Bangladesh demographic and health survey. 2014 data. Children. 2017;4(10):88.

16. Woldeamanuel BT, Tesfaye TT. Risk factors associated with under-five stunting, wasting, and underweight based on Ethiopian demographic health survey datasets in Tigray region, Ethiopia. Journal of nutrition and metabolism. 2019.

17. Wolde M, Berhan Y, Chala A. Determinants of underweight, stunting and wasting among schoolchildren. BMC Public Health. 2015;15(1):1-9.

18. Nigatu G, et al. Prevalence and associated factors of underweight among children 6-59 months of age in Takusa district, Northwest Ethiopia. Int J Equity Health. 2018;17(1):1-8.

19. Mulugeta A, et al. Child malnutrition in Tigray, northern Ethiopia. East Afr Med J. 2010;87(6):248-54.

20. Kebede D, et al., Prevalence of undernutrition and potential risk factors among children under 5 years of age in Amhara Region, Ethiopia: evidence from 2016 Ethiopian Demographic and Health Survey. Journal of Nutritional Science. 2021; 10.

21. Mengistu K, Alemu K, Destaw B. Prevalence of malnutrition and associated factors among children aged 6-59 months at Hidabu Abote District, North Shewa, Oromia Regional State. J nutr disorders ther. 2013;1:1-15.

22. Zeray A, Kibret GD, Leshargie CT. Prevalence and associated factors of undernutrition among underfive children from model and non-model households in east Gojjam zone, Northwest Ethiopia: a comparative cross-sectional study. BMC nutrition. 2019;5(1):1-10.

23. Chesire $E$, et al. Determinants of under nutrition among school age children in a Nairobi peri-urban slum. East Afr Med J. 2008;85(10):471-9.

24. Emmanuel A, et al., Malnutrition and associated factors among underfive in a Nigeria local government area. 2016.

25. Khan S, Zaheer S, Safdar NF. Determinants of stunting, underweight and wasting among children< 5 years of age: evidence from 2012-2013 Pakistan demographic and health survey. BMC Public Health. 2019;19(1):1-15.

26. Amare D, et al., Prevalence of undernutrition and its associated factors among children below five years of age in Bure Town, West Gojjam Zone, Amhara National Regional State, Northwest Ethiopia. Advances in Public Health. 2016.

27. Yisak H, Gobena T, Mesfin F. Prevalence and risk factors for under nutrition among children under five at Haramaya district, Eastern Ethiopia. BMC Pediatr. 2015;15(1):1-7.

28. Mgongo $\mathrm{M}$, et al. Underweight, stunting and wasting among children in Kilimanjaro Region, Tanzania; a population-based cross-sectional study. Int J Environ Res Public Health. 2017;14(5):509. 
29. Dasgupta A, et al. Assessment of under nutrition with composite index of anthropometric failure (CIAF) among under-five children in a rural area of West Bengal. Indian Journal of Community Health. 2014;26(2):132-8.

30. Amare $\mathrm{M}$, et al., Study of the determinants of chronic malnutrition in Northern Nigeria: quantitative evidence from the Nigeria demographic and health surveys international food policy research institute (IFPRI) working paper 45 (September 2017). Food and nutrition bulletin. 2018; 39(2): 296314.

31. Awoke A, Ayana M, Gualu T. Determinants of severe acute malnutrition among under five children in rural Enebsie Sarmidr District, East Gojjam Zone, North West Ethiopia, 2016. BMC nutrition. 2018;4(1):1-8.

32. Debeko DD, Goshu AT. Nutritional status of under-five children in Hawassa Zuria District, Southern Ethiopia. Am J Health Res. 2015;3(5):286-92.

33. Woldeamanuel BT, Tesfaye TT. Risk Factors Associated with Under-Five Stunting, Wasting, and Underweight Based on Ethiopian Demographic Health Survey Datasets in Tigray Region, Ethiopia. Journal of Nutrition and Metabolism. 2019; 6967170.

34. Asim M, Nawaz Y. Child malnutrition in Pakistan: evidence from literature. Children. 2018;5(5):60.

35. De Benoist B, et al., Worldwide prevalence of anaemia 1993-2005; WHO global database of anaemia. 2008.

36. Khan REA, Raza MA. Determinants of malnutrition in Indian children: new evidence from IDHS through CIAF. Qual Quant. 2016;50(1):299-316.

37. Genebo T, et al. The association of children's nutritional status to maternal education in Zigbaboto, Guragie Zone. Ethiop J Health Dev. 1999;13(1):55-6111. 